Boise State University

ScholarWorks

Sociology Faculty Publications and Presentations

Department of Sociology

9-1-2015

\title{
Alternative Food Networks and Food Provisioning as a Gendered Act
}

Rebecca L. Som Castellano

Boise State University 


\title{
Alternative Food Networks and Food Provisioning as a Gendered Act
}

\author{
Rebecca L. Som Castellano \\ Department of Sociology \\ Boise State University \\ Boise, Idaho \\ rsomcastellano@boisestate.edu
}

\begin{abstract}
Alternative food networks (AFNs) are exemplified by organic, Fair Trade and local foods, and promote forms of food provisioning that are 'corrective' to conventional agriculture and food (agrifood) systems. Despite enthusiasm for AFNs, scholars have increasingly interrogated whether inequalities are perpetuated by AFNs. Reproduction of gender inequality in AFNs, particularly at the level of consumption, has often been left empirically unexamined, however. This is problematic given that women continue to be predominantly responsible for food provisioning in the U.S., and that this responsibility can lead to negative physical, psychological and social outcomes. Using quantitative methods and data from the 2012 Ohio Survey of Food, Agriculture, and Environmental Issues, this paper examines the extent to which gender inequality in the division of labor is reproduced in AFNs by focusing on the potential persistence of gender inequality in food provisioning among AFN participants. Findings suggest that among AFN participants, particularly those utilizing local food systems, women, compared to men, remain predominantly responsible for food provisioning, spend more time in food provisioning, and engage in more food provisioning from scratch. This research confirms that food provisioning remains a gendered act amongst AFN participants, calling attention to the persistence of gender inequality in AFNs. The paper concludes by suggesting that AFNs are positioned as a place to create change, albeit small scale, in the gendered division of household labor in the U.S., and provides some practical suggestions for how this might occur.
\end{abstract}

Keywords: alternative food Networks; food provisioning, gender inequality; household division of labor

\section{Author Biography}

Rebecca L. Som Castellano, PhD, is an Assistant Professor in the Department of Sociology at Boise State University. Her research focuses on stratification and inequality in agrifood systems, the efficacy of alternative agrifood initiatives, and agrifood policy.

\section{Acknowledgements}

I would like to thank the editor, reviewers and Virginia Husting for their helpful comments on this paper, as well as Jeff Sharp, Linda Lobao, and Kristie Lekies for their guidance on the larger research project this paper emerged from. Financial support for this project was provided by USDA National Needs Graduate Fellowship Competitive Grant No. 2008-38420-18750 from the National Institute of Food and Agriculture and from the Coca-Cola Critical Difference for Women Grant. 


\section{Introduction}

Structural changes in the agriculture and food (agrifood) system, including industrialization, concentration and globalization, have altered how food is produced, distributed and consumed (Heffernan 2000; McMichael 2000; Levenstein 2003; Buttel 2006). These changes have prompted the rise of alternative food networks (AFNs) in the United States (U.S.) (Allen 2004; Goodman and Goodman 2009). AFNs promote forms of food provisioning that are 'corrective' to conventional agrifood systems, and are exemplified by "the explosion of organic, Fair Trade, and local, quality, and premium specialty foods” (Goodman and Goodman 2009, p. 9). Despite enthusiasm for AFNs, scholars have increasingly interrogated whether inequalities, particularly those related to social class or race and ethnicity, are perpetuated by AFNs (Hinrichs 2003; DeLind 2010). Reproduction of gender inequality in AFNs, particularly at the level of consumption, has often been left empirically unexamined, however. In particular, little attention to date has been paid to the division of labor in food provisioning amongst AFN participants not involved in agricultural production. Topics that have not been addressed include examination of how the division of labor in food provisioning for AFN participants varies by gender, sexuality, social class and race and ethnicity. This is problematic given that women continue to be overwhelmingly responsible for the vast majority of food provisioning in the U.S., (Lachance- Grzela and Bouchard 2010) and that this experience can vary significantly for women based on socio-demographic factors.

As part of a larger project examining the gendered labor of food provisioning in AFNs, this paper examines the degree to which women, compared to men, remain responsible for food provisioning in AFNs, and the amount of food provisioning labor women, compared to men, engage in among AFN participants. While this paper focuses on gender inequality in AFNs, and does not focus on the moderating effect of other factors like social class and race and ethnicity, it does establish the persistence of gender inequality in the division of labor in food provisioning among AFN participants, providing a foundation for future research which can further explore other issues, including the ways in which women engaged in AFNs differentially experience the gendered act of food provisioning based on factors like social class and race and ethnicity.

To understand the potential reproduction of gender inequality in food provisioning in AFNs, I begin by discussing the persistence and consequences of gender inequality in food provisioning in the U.S. I then describe the conceptual framework used to shape our understanding of the persistence of gender inequality in food provisioning in AFNs, employing a "doing gender" perspective to discuss how micro and macro processes reproduce gender inequality in everyday life. I then propose several hypotheses regarding the reproduction of gender inequality in food provisioning amongst AFN participants, and test these hypotheses with bivariate and multivariate analyses, using data from the 2012 Ohio Survey of Food, Agriculture, and Environmental Issues. Finally, I present the analyses, and provide conclusions directed towards improving our understanding of the ways in which AFNs can address issues of gender inequality in food provisioning.

\section{Background}

\section{Alternative Food Networks and Inequality}

Inequalities found in conventional agrifood systems persist in AFNs (Hinrichs 2003; Allen 2004; Edwards-Jones 2010). For example, AFN participants tend to be white, middle to upper class consumers, and AFNs often promote practices that fulfill racial and class hegemony (Hinrichs and Kramer 2002; Slocum 2007; Guthman 2011). This can limit participation by those who are not white and who are not middle or upper-middle class (DeLind 2010). However, despite increasing attention to issues of inequality in AFNs, gender inequality, particularly in the sphere of consumption, has received limited attention. A number of studies have examined women's roles in farming households (Whatmore 1991; Lobao and Meyer 1995; Sachs 1996; Meares 1997; Chiappe and Flora 1998; Trauger 2004; Cairns et al. 2010). This literature documents the multiple roles women play in farming households, focusing on the flexibility of women's labor, and the persistence of traditional gender roles both in farming and household tasks. For example, in their examination of farm families during the U.S. farm crisis of the 1980s, Lobao and Meyer (1995) found that gender inequality persisted in the division of household labor despite women's increasing engagement in off-farm employment. Moving beyond examination of farm families, however, gender in the sphere of consumption has gone largely ignored by alternative agrifood scholars (Lockie and Kitto 2000; Allen and Sachs 2007; Little et al. 2009). This reflects a larger critique of agrifood scholarship that the realm of production has been privileged over that of consumption (Lockie and Kitto 2000; Goodman and DuPuis 2002). Allen and Sachs (2007) 
assert that in regards to food studies and gender, "we find a rich literature in body politics and gendered eating patterns, but substantive gaps in the areas of structural issues and social change” (p. 1). Exceptions include agrifood scholars who have shown that women, compared to men, are more likely to visit farmers' markets, participate in CSA programs or buy local, and those who have focused on 'foodies' (DeLind and Ferguson 1999; Little et al. 2009; Cairns et al. 2010). A few scholars have theorized that gender inequality could be reproduced in AFNs, in part due to the continued inequality in household labor in the U.S. (Allen and Sachs 2007; Little et al. 2009; Deutsch 2011). However, beyond farm families no empirical research investigating gender inequality in food provisioning amongst AFN participants was found during the course of this research.

Gender Inequality and the Division of Labor in Food Provisioning

Throughout the $20^{\text {th }}$ century women's participation in formal employment increased dramatically (Andersen 2011). ${ }^{1}$ Despite this, women remain overwhelmingly responsible for housework (Bianchi et al. 2000). The hallmark scholarship of Arlie Hochschild (1989) has inspired a substantial body of literature on the persistence of gender inequality in the home. In her research, Hochschild (1989) described how women participating in paid employment were coming home to perform a 'second shift,' which included activities such as childcare and housework. More recent scholarship has found that this persistence of gender inequality in housework occurs even in egalitarian marriages, and among dual-career couples (Goldschneider and White 1991; Barnett and Rivers 1996; LachanceGrzela and Bouchard 2010). While men have increased the hours they spend in household labor (Bianchi et al. 2012), women remain responsible for ensuring that household tasks are completed (Avakian and Haber 2005). In addition, women remain overwhelmingly responsible for 'time-inflexible' tasks (Hook 2010), ${ }^{2}$ which are often more emotionally, mentally and physically demanding (Andersen 2011).

One of the most prominent time-inflexible household tasks is food provisioning (DeVault 1991; Hook 2010). Food provisioning, which involves physical, mental and emotional labor, includes planning of meals, procuring food, preparation of meals, and cleaning up after meals (DeVault 1991; McIntosh and Zey 1998; Avakian and Haber 2005). Women remain "overwhelmingly responsible" for family food provisioning; even in domestic situations where men take on some of the domestic labor, men are only "marginally involved with food provisioning activities" (DeVault 1991; Blake et al. 2009). While mothers are more likely to indicate that food provisioning is their responsibility, fathers are more likely to indicate that they 'help' with food provisioning (Blake et al. 2009).

\section{The Negative Consequences of Gender Inequality in Food Provisioning}

The skewed level of participation in food provisioning between men and women can have serious consequences (Coltrane 2000; Hook 2010). One negative consequence is that women's persistent responsibility for food provisioning reinforces gender inequality (Counihan 1999, 2005; Julier 2005). When women perform acts of food provisioning, they are engaging in traditionally feminine tasks, reinforcing ideological assumptions about who should be doing such work, reproducing gender inequality in their own households, as well as in larger society (Julier 2005). Further, the demands of multiple roles reduces the likelihood that women will achieve a professional career "on the same terms as men," and reduces the likelihood that women can achieve parity in terms of status and wages in the public sphere (Lundberg 1996, p.117; Hook 2010). When women are unable to achieve a professional career on the same terms as men, they are less able to have economic power, which is essential in achieving gender equality in the household, and in greater society (Blumberg 1984; Hook 2010).

A second negative consequence of women's persistent responsibility for food provisioning is that the demands of multiple roles, particularly roles that are time-inflexible, can decrease physical and mental well-being (Bird 1999; Coltrane 2000; Lundberg 2002, 2005; Hook 2010). Responsibility for routine and repetitive chores such as cooking can lead to an increased sense of burden or demand, which can lead to higher levels of distress (Bolger et al. 1989; Barnett and Shen 1997). The more responsibility women have for these tasks, the more they report the work as demanding and stressful (Lennon et al. 1990; Lennon and Rosenfield 1994). This stress and sense of demand can in turn impact physical well-being, including cardiovascular and musculoskeletal disorders (Lundberg 1996). In addition, inequality in housework can affect marital outcomes (Breen and Prince Cooke 2005). Scholars have found

\footnotetext{
${ }^{1}$ Poor women, women of color, and immigrant women have long worked for pay, and the rise of employment in the $20^{\text {th }}$ century was dominated by white, middle and upper middle class women (Duffy 2007; Andersen 2011).

${ }^{2}$ Time inflexible tasks are those that must be done at regular intervals and often at specific times of the day.
} 
a connection between women being held responsible for food provisioning, but men dominating the organization of eating and cooking (McIntosh and Zey 1998), and dissatisfaction with how women provision food has been linked to violence in the home (Bell and Valentine 1997). Food provisioning, particularly for women, can also be an important part of enacting and maintaining identity and providing care and nourishment for loved ones (DeVault 1991; Counihan 1999, 2005). The necessity of engaging in gendered practices to enact identity and show care can also add to the physical and mental strain of food provisioning (Counihan 2005; Shapiro 2005). Thus, there are serious physical, social and psychological consequences when there are increased burdens on women in the domestic sphere.

The negative consequences of food provisioning can impact all women, but could be particularly problematic for AFN participants. Women often feel guilty when they are unable to meet normative food provisioning ideals (DeVault 1991; Avakian and Haber, 2005; Blake et al. 2009; Cairns et al. 2013). AFN participants often aim to engage in more from scratch food provisioning, rather than utilizing processed or convenience foods (Murdoch and Miele 2004; Little et al. 2009). AFN participants have also been found to provision seasonally, self-provision through home or community gardens, provision at a wider variety of venues, such as farmers' markets, and/or engage in food preservation activities, such as canning or drying (Feenstra 1997; Click and Ridberg 2010). As noted below, AFN participants also prioritize provisioning foods that are grown organically, or that are produced and distributed locally. Given these heightened standards for food provisioning, the negative consequences of food provisioning, including the potential physical, social physiological impacts of taking on multiple roles, can be amplified for AFN participants (Som Castellano 2013). These negative consequences provide compelling reasons to be concerned with the potential reproduction of gender inequality in AFNs. Examining the potential persistence of gender inequality in AFNs is further important given the growth in AFN participation in recent years (Martinez et al. 2010; Mount 2012).

\section{Conceptualizing the Reproduction of Gender Inequality}

In order to conceptualize the reproduction of gender inequality in food provisioning, I employ a "doing gender" perspective, which views gender as a practice, embedded in routine tasks and everyday interaction (West and Zimmerman 1987). One way that women do gender is by engaging in traditionally female tasks in the household (Risman 2009). A number of feminist food scholars have employed the "doing gender" approach, finding that women engage in doing gender when they perform acts of food provisioning, a task historically delegated to women (DeVault 1991; Julier 2005; Avakian and Haber 2005).

The "doing gender" perspective can help us understand how gender inequalities are maintained and reproduced through micro and macro level processes. While women reproduce unequal gender relations via activities like food provisioning, they are also constrained by social structures. Gender inequality is built into social structure, which prescribes proper forms of conduct for people based on their social roles, socializing men and women to enact gender norms (Epstein 1988; Ferree 2010; Lorber 2010), such as providing food for their families. Social structures also influence the perceived worth of a given activity, which further influences the reproduction of gendered tasks. For example, definitions of masculinity can be associated with the 'economic provider role,' which has been historically more valued in the U.S. (Epstein 1988). This can lead to men resisting tasks defined as feminine (Bianchi and Milkie 2010). Thus, how individuals do gender can be constrained by social structure, and can reinforce patriarchal privilege (Ferree 2010; Lorber 2010). When women engage in traditionally female tasks in the household, such as food provisioning, they in turn reproduce gendered norms, male privilege, and power (Risman 2009). The "doing gender" perspective supports the notion that women in AFNs would continue to be responsible for food provisioning, and would continue to engage in more food provisioning labor, given the persistence of gender inequality in the U.S.

Social structure further perpetuates inequality in the household division of labor via stratification based on social class and race and ethnicity (Avakian and Haber 2005). For example, scholars have argued that gender inequality can be purchased through the commercial marketplace, documenting that higher income women are able to achieve heightened standards of cleanliness and address gender inequality in the division of labor by hiring lower income women of color to do the work for them (Anderson 2000). This scholarship would suggest that among AFN participants, women with higher incomes would be less likely to experience gender inequality in food provisioning. Despite the power of social structures in maintaining gender inequality in the household division of labor, gender norms and ideals are not static. Risman (2009) notes that the undoing of gender must be documented, and Lorber 
(2010) asserts that "as the social order changes, and as we participate in different social institutions and organizations throughout our lives, our gendered behavior changes” (p. 9). By examining whether gender inequality persists in AFNs, I am interrogating whether participating in a new social institution or organization, particularly one that is considered post-materialist, ideologically progressive and challenges the status quo of conventional agrifood (Allen and Sachs 2007), is associated with changes in a form of gendered behavior.

\section{Proposed Research Questions and Hypotheses}

Based on the above background literature, three hypotheses guide this analysis:

H1: Among AFN participants, women, compared to men, are more likely to be responsible for the labor of food provisioning.

H2: Among AFN participants, women, compared to men, spend more time in food provisioning

H3: Among AFN participants, women, compared to men, engage in more food provisioning from scratch.

\section{Data and Methods}

Data for this project comes from the 2012 Ohio Survey of Food, Agriculture and Environmental Issues. This is a biennial mail survey of households throughout rural and urban Ohio. The survey is designed and administered by a team of faculty, graduate students and staff at the Ohio State University. The 2012 Ohio Survey was a 12 page booklet with 155 questions. Data for the 2012 Ohio Survey was collected during the spring and summer of 2012. A statewide sample of 2,000 Ohio households was selected and stratified according to metropolitan core and nonmetropolitan county status. A sample of 1,000 residents in specific zip codes in Ohio known to have active engagement in AFN institutions was also selected. The combined initial sample size was 3,000.

The main objective of the Ohio Survey is to measure Ohioans attitudes on a range of contemporary food, farming and environmental issues. Previous versions of the survey have assessed agrifood system concern, as well as engagement in AFNs. Standard demographic items have also been previously included on the survey instrument. These established items were used in this project to assess respondent's engagement in alternative agrifood practices and their demographics. In addition, I designed several items which were added to the 2012 Ohio Survey to assess beliefs, attitudes and behaviors surrounding the food provisioning practices of respondents. These items allowed for the assessment of the gendered division of labor in food provisioning for those engaged in AFNs.

The data collection methodology was guided by a modified version of Dillman's Tailored Design Method (Dillman 2000). A total of 771 surveys were returned, for a response rate of $28 \%$. Due to systematic missing data on surveys, the final sample size was 703 , for a $23 \%$ response rate. The data used for this study was weighted to account for the disproportionate sampling of certain zip codes and counties and to ensure that the data appropriately represents the characteristics of the population of Ohio. Comparisons between survey respondent demographics and the 2010 American Community Survey (ACS) were conducted to assess the degree to which sample respondents mirrored the adult population of Ohio (Table 1).

$$
<<\text { Table } 1 \text { about here }>>
$$

\section{Measuring AFN Engagement}

This project aims to model the relationship between gender and the labor of food provisioning for those engaged in AFNs. Therefore, this research uses both the entire sample as described above, as well as two sub-samples of survey respondents who reported AFN engagement. As noted above, AFNs are spaces within the food economy that have formed as alternatives to the conventional agrifood system. AFNs have become imbued with values and ethical norms (DuPuis and Goodman 2005), and AFN participants engage in reflexive consumption, provisioning products that are produced, processed, distributed and consumed under specific conditions (DuPuis 2000; Goodman and Goodman 2009; Brunori et al. 2012). However, AFNs have been found to be diverse and dynamic, and different 
AFNs highlight different concerns with the agrifood system (Renting et al. 2003; Goodman and Goodman 2009). Organic and local ${ }^{3}$ in particular have been identified as attributes that are important to consumers engaged in AFNs (Ostrom 2006; Goodman and Goodman 2009; Bean and Sharp 2011; Renting et al. 2003).

Historically there was a blurring between local and organic; however, increasingly studies have found support "for local food as distinct and separate from organic food” (Adams and Salois 2010). Over time, small farmers have been marginalized from the benefits of organic as large corporations have become involved in the production and distribution of organic products, and many consumers have shifted to prioritizing local foods, which are viewed as "a more holistic and authentic substitute for organic" (Adams and Salois 2010, p.333). Currently, consumers prioritizing organic products tend to be more concerned with consumer health and safety, the environment, as well as attributes like price, taste, and appearance. Consumers who prioritize local foods tend to be concerned with a broader social and environmental mission, expressing concern for farmers, workers, animal welfare, or rebuilding communities (Adams and Salois 2010; Bean and Sharp 2011). Where people provision food can also be shaped by a focus on organic or local. $70 \%$ of the sale of organic products occurs in grocery stores or supermarkets in the UK (Goodman and Goodman 2009), while shoppers at farmers' markets are more likely to report that locally grown food is very important to them, and are less likely to report that organically grown food is important to them (Adams and Salois 2010). Thus, while there can be some overlap between these two categories (Bean and Sharp 2011), this literature suggests that attention should be paid to two categories of AFN participants: those who prioritize organic products, and those who prioritize products that are local.

Two indices were therefore created to assess engagement in AFNs. These indices were constructed from questions that asked about the frequency of food provisioning behaviors related to local and organic food purchases. ${ }^{4}$ Respondents were asked, "Thinking about this past year (2011), how often did you engage in the following activities?” Four items in this series of questions were used in the two measures used to assess AFN participation:
a) Buy foods that are locally grown or produced,
b) Buy foods labeled as certified organic,
c) Attend a farmers' market,
d) Shop at an organic or natural grocery store (such as Whole Foods) or a food coop.

Response categories ranged from (1) never, to (5) more than 10 times. Confirmatory factor analysis was conducted on these four items and the case loadings confirmed the appropriateness of creating two distinct indices from these items. In addition, the correlation between the two indices was low (0.37). As noted above, it is possible that a small number of individuals could fall into both categories. However, the above literature provides compelling reasons to consider the gender division of labor in food provisioning for these two forms of AFN participation separately. The two indices are described in detail below.

Measure 1: Frequency of Purchasing Local \& Shopping Via Direct Markets. Factor analysis confirmed that the individual items related to purchasing local foods and shopping via direct markets were interrelated and Cronbach's alpha further confirmed that the reliability of combining these items into a scale was acceptable (alpha reliability=.77). This resulted in the measure "Frequency of Purchasing Local and Shopping via Direct Markets." This scale had a range of 2 to 10, with low scores representing little to no engagement in AFNs and high scores representing active participation in AFNs. The mean for this variable was 6.7, with a standard deviation of 2.2.

\footnotetext{
${ }^{3}$ The term "local" has a geographic connotation, as well as relational and qualitative elements. While there is debate about the distance that should exist between production and consumption in order for an agrifood item to be considered "local" (Ostrom 2006; Adams and Salois 2010), the U.S. Congress adopted a definition in the 2008 Food, Conservation and Energy Act, asserting that the an agrifood product can still be considered locally or regionally produced if the distance it is transported does not exceed 400 miles, or if it is transported within the state in which it is produced (Martinez 2010).

${ }^{4}$ Engagement in AFNs can be assessed both attitudianally and behaviorally, but there can be a gap between an individual's concern with the agrifood system, and their subsequent behavior (Vermier and Verbeke 2006). Therefore, only behavioral measures of engagement in AFNs were used in this analysis.
} 
Measure 2: Frequency of Purchasing Organic and Shopping at Natural Grocery Stores. Factor analysis also confirmed that individual items related to purchasing organic foods and shopping at natural grocery stores were interrelated and Cronbach's alpha further confirmed the reliability of combining these items into a scale was acceptable (alpha reliability =.77). This resulted in the measure "Frequency of Purchasing Organic and Shopping via Natural Grocery Stores.” This scale also has a range of 2 to 10 with low scores representing little to no engagement in AFNs and high scores representing active participation in AFNs. The mean of this variable was 4.9, with a standard deviation of 2.7 .

Both of these measures were used separately to modify the sample in order to assess differences in the labor of food provisioning for those engaged in AFNs, and those not engaged. For each measure, the sample was reduced by dropping those with low scores (less than 7).

\section{Variables for Bivariate Analyses}

To examine the hypothesized relationships of interest, the first set of analyses examined the bivariate relationships between responsibility for food provisioning and gender. To measure gender, respondents were asked to report whether they identified as male or female. This variable was dichotomized, with male $=0$ and female $=1$. To measure responsibility for food provisioning, respondents were asked who in their household was primarily responsible for four different aspects of food provisioning: (1) planning meals; (2) shopping for food; (3) cooking; and (4) cleaning up after meals. Four response categories were offered, including (1) you; (2) your spouse or partner; (3) you and your partner; (4) other. The descriptive statistics for all variables used for bivariate analyses can be found in Table 2 .

\section{Variables Used for Regression Analyses}

To further examine the hypothesized relationships of interest, a number of regression analyses were conducted. Below, I describe the variables used for these models. The descriptive statistics for all variables used for regression analyses can be found in Table 2 .

\section{Dependent Variables}

The central dependent variables for the regression analyses capture the physical labor of food provisioning. The first item captures the amount of time respondents spent in food provisioning on a daily basis. Respondents were asked, "On average, how many minutes each day do you spend planning meals, acquiring food (shopping, picking up a CSA share, etc.), preparing and cooking food, and cleaning up after meals?___ Minutes (if no time is spent on these tasks, please write "0"). The mean of time spent in food provisioning was 66.2 , with a range of $0-300$ minutes and a standard deviation of 47.2 .

In addition to time, using whole, unprocessed foods, or engaging in 'from scratch cooking,' can also capture the physical labor of food provisioning. Therefore, the second item used to measure the physical dimension of food provisioning is respondent's self-reported proportion of food provisioning from scratch. Respondents were asked: "What proportion of the food you prepare daily is made from scratch? (if none of the food you prepare is made from scratch, please write " 0 ")__ \%." The mean for proportion from scratch was 40.8, with a range of 0-100, and a standard deviation of 32.4.

\section{Independent Variables}

The central independent variable of interest for this analysis is gender, which was described in detail above.

\section{Control Variables}

In the regression models I controlled for a number of standard socio-demographic factors identified in scholarly literature as being related to the labor of food provisioning, including socio-economic status, partnership status, employment status, race/ethnicity, and age. Descriptive statistics for these variables can be found in Table 2. In addition, I controlled for other factors that have been identified as being related to the gender division of labor, and the labor of food provisioning. Below, I describe how these control variables are operationalized in the quantitative analysis. 
Gender Ideology. There can be an association between gender role ideology and the gender division of domestic labor (Barnett and Shen 1997; Crompton et al. 2005). To measure gender ideology, respondents were asked, "On a scale from 1 to 7 , how much do you agree with the following statement: "It is much better for everyone if the man earns the main living and the woman takes care of the home and family." ${ }^{5}$ Responses ranged from 1 to 7 , with a mean of 3.0 .

Human Health Concern. Human health concern can influence the types of foods individuals purchase (Schifferstein and Ophus 1998; Magnusson et al. 2003), and could add to the labor of food provisioning. For this reason, I combined three survey items into a scale to control for human health concern. Respondents were asked to "Please indicate your level of agreement with the following statements related to the food you eat and your health: (1) I consider myself health conscious; (2) I am interested in using food to maintain health; and (3) I usually look for health information when I buy food products." Response categories ranged from "Strongly Disagree" (1) to "Strongly Agree" (5). Factor analysis confirmed that these items were interrelated and that the reliability of combining them into a scale was acceptable (alpha reliability $=0.79$ ). This variable had a range of 3 to 15 , a mean of 11.9 , and a standard deviation of 2.1 .

$<<$ Table 2 about here $>>$

\section{Analyses and Results}

To test the hypotheses, I first conducted bivariate comparisons of responsibility for food provisioning and gender for the entire sample, as well as the two sub-samples. To further test the hypotheses, regression analyses were conducted, in order to determine the existence of a relationship between gender and the physical labor of food provisioning, net the effect of other factors.

\section{Bivariate Analyses}

I conducted bivariate analyses by doing simple cross tabulations, in order to explore how the relationship between gender and responsibility for food provisioning varies based on engagement in AFNs. I looked at four types of responsibility for food provisioning: (1) planning of meals; (2) shopping for food; (3) cooking; and (4) cleaning up after meals, and examined the degree of responsibility men and women had for each of these tasks. In order to assess statistical significance for the cross tabulations, chi-squared statistics were calculated. Almost all of the cross tabulations were highly significant, with p-values equal to or less than .001. The only exception was the responsibility for cleaning variable for the engaged organic sample, which was not significant. The results of the bivariate analyses can be found in Table 3 .

Overall, the bivariate results indicate that gender inequality in food provisioning persists among those engaged in AFNs. This is particularly evident among those who engage in local food system initiatives. Among those engaged in local food systems, a greater proportion of women are responsible for planning meals, shopping for food, and cooking. The proportion of men responsible for planning, shopping, cooking and cleaning decreases amongst those engaged in local food system initiatives. The proportion of work that is shared stays the same in the categories of planning and shopping, but slightly increases for the categories of cooking and cleaning. For those who purchase organic foods and shop at natural grocery stores, the same proportion of women are responsible for acquiring foods, while slightly fewer women are responsible for planning, cooking and cleaning. In this subsample the proportion of men who are responsible for planning, shopping, and cooking decreases, but there is an increase in the sharing of all three of these categories of work. ${ }^{6}$ When interpreting these results, it is important to note that women tend to underreport responsibility for and time spent in food provisioning, while men have been found to over-report time spent in housework (DeVault 1991; Kan 2008).

\section{$<<$ Table 3 about here $>>$}

\footnotetext{
${ }^{5}$ Ideally, gender ideology is measured using a variable created from a number of measures. However, due to space limitations on the survey instrument, only one item could be used to measure gender ideology. The measure of gender ideology used in this research has been used by many scholars in previous work to examine gender ideology (i.e. Blair and Johnson 1992; Greenstein 1996; Sanchez and Thomson 1997).

${ }^{6}$ As noted, the cleaning variable was not significant in this model, and therefore these results are not discussed.
} 


\section{$\underline{\text { Regression Analysis }}$}

Regression analysis provides a more nuanced understanding of the relationship between gender and the labor of food provisioning for those engaged in AFNs. In total, six sets of regression analyses were conducted. The results of the regression analyses are presented as coefficients and standardized coefficients in Table 4. Only statistically significant results are discussed here. The first two regression models show the relationship between gender and time spent in food provisioning (Model 1) and the relationship between gender and the proportion of food provisioning from scratch (Model 2) for the entire sample. According to Model 1, women, compared to men, on average spend almost 20 more minutes in food provisioning per day. Having children over the age of 4, having a partner, being a home owner, and human health concerns were also positively associated with time spent in food provisioning, while being employed was negatively associated with time spent in food provisioning. According to Model 2, being a woman was also positively associated with engaging in food provisioning from scratch; women, compared to men, engage in 13.8 percent more food provisioning from scratch. Human health concern was also positively associated with food provisioning from scratch.

The next two models were based on analysis of only those persons actively engaged in local food systems ( $\mathrm{n}=362$ ). In Model 3, a positive relationship again existed between women and time spent in food provisioning. In addition, having children and having human health concerns were positively associated with time spent in food provisioning, while employment was again negatively associated with time spent in food provisioning. In Model 4, a positive relationship existed between women and percentage of food provisioning from scratch. In addition, human health concern was positively associated with food provisioning from scratch.

The final two models were based on analysis of those persons actively engaged in support of organic foods and natural grocery stores $(\mathrm{n}=181)$. In Model 5 a positive and significant relationship again existed between women and time spent in food provisioning. In addition, having children was also positively associated with time spent in food provisioning. Model 6 was not significant

According to the standardized coefficients, in Models 1, 3 and 5, gender was the most important factor associated with time spent in food provisioning. In Models 2 and 4, which all examined the relationship between gender and proportion of food provisioning from scratch, gender was the second most important factor, with human health concern being the most important.

$$
<<\text { Table } 4 \text { about here }>>
$$

\section{$\underline{\text { Summarizing the Results }}$}

These results provide support for the above stated hypotheses. Hypothesis 1, which asserted that among AFN participants women, compared to men, are more likely to be responsible for the labor of food provisioning, was tested using bivariate analyses. The bivariate results suggest that compared to men, women engaged in AFNs, particularly those engaged in local food systems, remain predominantly responsible for all aspects of food provisioning (planning, procuring foods, cooking and cleaning) examined, providing support for this hypothesis.

Hypothesis 2, which asserted that among AFN participants, women, compared to men, will spend more time in food provisioning, was confirmed. In all regression models, there was a positive and statistically significant relationship between women and time spent in food provisioning per day. Hypothesis 3, which asserted that among AFN participants, women, compared to men, will engage in more food provisioning from scratch, was also confirmed. In all but one of the regression models there was a positive and statistically significant relationship between women and the proportion of food provisioning from scratch.

Other independent variables also produced interesting results. For example, those engaged in local food systems with young children labor an additional 15 minutes in food provisioning. This additive effect does not occur for those who are not engaged in AFNs. Further, as noted above, previous scholarship would suggest that among AFN participants, those with higher incomes would be less likely to experience gender inequality in food provisioning. However, none of the coefficients related to socio-economic status were statistically significant for the subsamples representing those engaged in AFNs. I further tested for a relationship between gender, income, and the labor of 
food provisioning by running an interaction effect. However, the results did not support the supposition that among AFN participants, higher income women would be less likely to experience gender inequality in food provisioning as the coefficients were not significant.

\section{Discussion and Conclusion}

The findings presented here offer insight into theoretical debates within the field, best practices when promoting AFN initiatives, as well as important avenues for further research. First, this project builds on scholarship examining the reproduction of social inequalities in AFNs. To date agrifood scholarship has largely overlooked the persistence of gender inequality in food provisioning amongst AFN participants in the sphere of consumption. While this study is narrow, it nevertheless helps fill this gap in the literature by examining the degree to which women, relative to men, remain responsible for food provisioning amongst AFN participants, the amount of time women, compared to men, spend in food provisioning for those engaged in AFNs, and the amount of from scratch food provisioning women, compared to men, engaged in AFNs do. Consistent with my expectations, the findings presented here confirm that amongst those engaged in AFNs, women, compared to men, continue to be responsible for food provisioning, spend more time in food provisioning and engage in more food provisioning from scratch. These findings suggest that food provisioning remains a gendered act amongst those engaged in AFNs, particularly those who prioritize local food systems, and that a form of gender inequality that is found in broader U.S. culture is at times reproduced by AFN participants.

This research confirms, albeit in a small way, that gender inequality in food provisioning persists in AFNs, which can in part be explained by the powerful mechanisms which reproduce gender inequality in the division of labor in the U.S. As noted above, how individuals do gender can be constrained by social structure, and can reinforce patriarchal privilege (Ferre 2010; Lorber 2010). Social structure influences the perceived worth of labor done in the private versus the public spheres (England 2010), and in large part shapes who becomes socialized into household tasks and how people do gender. In turn, women do gender by engaging in food provisioning, reproducing gender inequality in the division of labor in the home, in AFNs, and in larger society. Importantly few social incentives have encouraged men to take up traditionally feminine tasks, activities culturally defined as feminine continue to be devalued, and therefore little institutional change has occurred in traditionally female activities (England 2010). The data presented in this paper suggests that little institutional change is occurring in the gendered division of labor in food provisioning in AFNs, as well.

The results presented here may be helpful for those concerned with improving equality in the agrifood system. As argued at the beginning of this article, the persistence of gender inequality in food provisioning is problematic given the potential negative physical, psychological and social outcomes of women's continued responsibility for such labor. Creating large scale social change in the gendered division of labor in food provisioning is a large undertaking which extends beyond the reach of AFNs. However, AFNs provide a space which allows for critique of the agrifood system. Further, as noted above the reproduction of gender inequality involves interaction between micro and macro level processes. Therefore, AFNs provide a location through which change can be attempted, albeit in small way. There are numerous ways in which this could occur. For example, AFN leaders could play a role in creating change. AFN leaders such as Michael Pollan have called for individuals to engage in critical consumption and increased home cooking. However, such leaders often fail to acknowledge who is responsible for the day to day labor of food provisioning and the consequences of this labor. As Deutsch (2011) notes, "the division of responsibilities among household members is at best an afterthought — not the problem that must be solved” (p. 169). AFN leaders could potentially help create change in the unequal gender division of labor in AFNs by acknowledging and drawing attention to who is provisioning food for families, highlighting gender inequality in food provisioning as a problem that must be solved.

In addition, AFNs could address this problem by ensuring that AFN policies and programs are aimed at both men and women. From an early age, girls are socialized to be caregivers through food provisioning, and are also taught the skills needed to provision food (Basow 1992; Witt 1997). This contributes to the trend of men 'helping out' with food provisioning while women remain responsible for food provisioning (Blake et al. 2009). One way to increase men's participation in food provisioning is to socialize them into the labor of food provisioning from an early age, and to ensure that programs and policies encourage both men and women to be involved in food provisioning. There are numerous alternative agrifood programs and policies created and implemented at national and local scales which could help in such an effort. Take, for example, farm-to-school programs, which often promote educational 
activities for children related to food preparation, often with a focus on utilizing local foods. Such programs could potentially help improve gender inequality in food provisioning by ensuring that boys are involved as seriously as girls in learning food provisioning skills.

While this study provides insight on the relationship between gender inequality in food provisioning and AFN participation, there are several limitations which future research should address. First, the sample population for the 2012 Ohio Survey was drawn from residents of the state of Ohio, providing some potential limitations in regards to the generalizability of the findings presented here. Future research could utilize national data to explore the relationship between the reproduction of gender inequality and AFN participation. Second, a larger sample size could provide more robust findings. Third, the project is heteronormative, as the focus is on heterosexual partnerships and household. Future research could further investigate the division of labor in food provisioning in same-sex partnerships among AFN participants.

An additional limitation is that the research presented here has a narrow focus and is therefore limited in its scope. In particular, this study does not thoroughly examine the ways in which social class and race and ethnicity influence the relationship between gender and food provisioning for AFN participants, nor other factors which can influence how women engaged in AFNs experience the labor of food provisioning. However, establishing that food provisioning remains a gendered act for AFN participants provides a basis for exploring other issues, including (1) how the labor of food provisioning differs for women engaged in AFNs, versus those who are not, and (2) how women engaged in AFNs experience their food provisioning labor differently based on factors such as SES and race and ethnicity. This is important research that should follow. Future research should also explore, both quantitatively and qualitatively, other dimensions of food provisioning (such as the mental and emotional dimensions), and how these dimensions are influenced by AFN participation. In addition, it would be worthwhile to explore how other household forms engaged in AFNs experience the labor of food provisioning, including two or three generation households, single parent households, households with grown children, and same-sex households.

This study could inspire a number of other potential research projects as well. For example, it would be worthwhile to engage in cross cultural, comparative research. Agrifood system concerns are a global phenomenon, social movements are forming around the world to respond to the changing agrifood system, and women remain predominantly responsible for food provisioning around the world. Therefore, it would be interesting to understand how women across the world are experiencing food provisioning given increasing agrifood system concerns and AFN participation.

\section{References}

Adams, D. C., and M.J. Salois. 2010. Local versus organic: A turn in consumer preferences and willingness-to-pay. Renewable Agriculture and Food Systems 25(4): 331-341.

Allen, P. 2004. Together at the table: Sustainability and sustenance in the American agrifood system. University Park, PA: The Pennsylvania University Press.

Allen, P., and C. Sachs. 2007. Women and food chains: the gendered politics of food. International Journal of Sociology of Food and Agriculture 15 (1): 1-23.

Andersen, M. 2011. Thinking about women: Sociological perspectives on sex and gender. Boston, MA: Allyn and Bacon.

Anderson, B. 2000. Doing the dirty work?: The global politics of domestic labour. London, UK: Zed Books.

Avakian, A. V., and B. Haber, eds. 2005. From Betty Crocker to feminist food studies: Critical perspectives on women and food. Amherst, MA: University of Massachusetts Press.

Barnett, R., and C. Rivers. 1996. She works/he works: How two-income families are happier, healthier and better off. San Francisco, CA: Harper.

Barnett, R., and Y. Shen. 1997. Gender, high- and low-schedule-control housework tasks, and psychological distress. Journal of Family Issues 18(4): 403-428.

Basow, S.A. 1992. Gender stereotypes and roles. Pacific Grove, CA: Brook/Cole.

Bean, M., and J. S. Sharp. 2011. Profiling alternative food system supporters: The personal and social basis of local and organic food support. Renewable Agriculture and Food Systems 26 (03): 243-254.

Bell, D., and G. Valentine. 1997. Consuming geographies. London, UK: Routledge.

Bianchi, S.M., and M. Milkie. 2010. Work and family research in the first decade of the 21st century. Journal of Marriage and Family 72(3): 705-725. 
Bianchi, S.M., M. Milkie, L. Sayer, and J. Robinson. 2000. Is anyone doing the housework: Trends in the gender division of household labor. Social Forces 79(1): 191-228.

Bianchi, S.M., L.C. Sayer, M. Milkie, and J.P. Robinson. 2012. Housework: Who did, does or will do it, and how much does it matter? Social Forces 91(1): 55-63.

Bird, C.E. 1999. Gender, household labor, and psychological distress: The impact of the amount and division of housework. Journal of Health and Social Behavior 40: 32-45.

Blair, S., and M. Johnson. 1992. Wives' perceptions of fairness and the division of household labor. Journal of Marriage and the Family 54: 570-581.

Blake, C., C. Devine, E. Wetherington, M. Jastran, T. Farreu, and C. Bisogni. 2009. Employed parents satisfaction with food-choice coping strategies: Influence of gender and structure. Appetite 52 (3): 711-719.

Blumberg, R.L. 1984. A general theory of gender stratification. Sociological Theory 2: 23-101.

Bolger, N., A. DeLongis, R.C. Kessler, and E. Worthington. 1989. The contagion of stress across multiple roles.” Journal of Marriage and the Family 51: 175-183.

Breen, R., and L. Prince Cooke. 2005. The persistence of the gendered division of domestic labour.” European Sociological Review 21(1): 43-57.

Brunori, G., A. Rossi, and F. Guidi. 2012. On the new social relations around and beyond food: Analysing consumers' role and action in Gruppi di Acquisto Solidale (Solidarity Purchasing Groups). Sociologia Ruralis 52 (1): 1-30.

Buttel, F. 2006. Sustaining the unsustainable: agro-food systems and environment in the modern world. In Handbook of Rural Studies, eds. P. Cloke, T. Marsden and P. Mooney, 213-229. London, UK: Sage Publications.

Cairns, K., J. Johnston, and S. Baumann. 2010. Caring about food: Doing gender in the foodie kitchen. Gender and Society 24 (5): 591-615.

Cairns, K., J. Johnston, and N. MacKendrick. 2013. Feeding the 'organic child': Mothering through ethical consumption. Journal of Consumer Culture 13 (2): 97-118.

Chiappe, M.B. and C. Butler Flora. 1998. Gendered elements of the alternative agriculture paradigm. Rural Sociology 49:183-209.

Click, M.A., and R. Ridberg. 2010. Saving food: Food preservation as alternative food activism. Environmental Communication 4(3): 301-317.

Coltrane, S. 2000. Research on household labor: Modeling and measuring the social embeddedness of routine family work. Journal of Marriage and Family 62: 1208-1233.

Counihan, C.M. 1999. The anthropology of food and body: Gender, meaning and power. New York, NY: Routledge.

Counihan, C.M. 2005. The border as barrier and bridge: Food, gender, and ethnicity in the San Luis Valley of Colorado. In From Betty Crocker to feminist food studies: Critical perspectives on women and food, eds. A.V. Avakian and B. Haber, 200-217. Amherst, MA: University of Massachusetts Press.

Crompton, R., M. Brockmann, and C. Lyonette. 2005. Attitudes, women's employment and the domestic division of labour: A cross-national analysis in two waves. Work, Employment and Society 19:213-33.

Delind, L.B. 2010. Are local food and the local food movement taking us where we want to go? Or are we hitching our wagons to the wrong stars. Agriculture and Human Values 28 (2): 273-283.

DeLind, L., and A. Ferguson. 1999. Is this a women's movement? The relationship of gender to community supported agriculture in Michigan. Human Organization 58 (2): 190-200.

Deutsch, T. 2011. Memories of mothers in the kitchen. Radical History Review 110: 167-177. DeVault, M. 1991. Feeding the family: The social organization of caring work. Chicago, IL: University of Chicago Press.

Dillman, D. 2000. Mail and internet surveys: The tailored design method. New York, NY: John Wiley \& Sons, Inc.

Duffy, M. 2007. Reproducing labor inequalities: Challenges for feminists conceptualizing care at the intersections of gender, race, and class. Gender and Society 19 (1): 66-82.

Dupuis, E.M. 2000. Not in my body: rBGH and the rise of organic milk. Agriculture and Human Values 17 (3): 285295.

DuPuis, E.M. and D. Goodman. 2005. Should we go "home” to eat?: toward a reflexive politics of localism. Journal of Rural Studies 21 (3): 359-371.

Edwards-Jones, G. 2010. Does eating local food reduce the environmental impact of food production and enhance consumer health? Proceedings of the Nutrition Society 69: 582- 591.

England, P. 2010. The gender revolution uneven and stalled. Gender \& Society 24 (2): 149-166. Epstein, C.F. 1988. Deceptive distinctions: Sex, gender, and the social order. New Haven, CT: Yale University Press. 
Feenstra, G. 1997. Local food systems and sustainable communities. American Journal of Alternative Agriculture 12 (1): 28-36.

Ferree, M.M. 2010. Filling the glass: Gender perspectives on families. Journal of Marriage and Family 72 (3): 420 439.

Heffernan, W.D. 2000. Concentration of ownership and control in agriculture. In Hungry for profit: The agribusiness threat to farmers, food and the environment, eds. F. Magdoff, J. Bellamy Foster and F.H. Buttel, 61-75. New York, NY: Monthly Review Press.

Goldschneider, F., and L. White. 1991. New families, no families: The transformation of the American home. Berkeley, CA: University of California Press.

Goodman, D., and E.M. DuPuis. 2002. Knowing food and growing food: beyond the production- consumption debate in the sociology of agriculture. Sociologia Ruralis 42 (1):5-22.

Goodman, D., and M. Goodman. 2009. Alternative food networks. In International encyclopedia of human geography, eds. R. Kitchin, and N. Thrift, 208-220. Oxford, UK: Elsevier.

Greenstein, T.N. 1996. Gender ideology and domestic labor: Effects on marital quality. Social Forces 74: 10291042.

Guthman, J. 2011. 'If they only knew': The unbearable whiteness of alternative food. In Cultivating food justice: Race, class and sustainability, eds. A.H. Alkon and J. Agyeman, 263 - 282. Boston, MA: Massachusetts Institute of Technology.

Hinrichs, C.C. 2003. The practice and politics of food system localization. Journal of Rural Studies 19: 33-45.

Hinrichs, C.C., and K. Kremer. 2002. Social inclusion in a Midwest local food system project. Journal of Poverty 6: 65-90.

Hochschild, A. 1989. The second shift. New York, NY: Viking.

Hook, J.L. 2010. Gender inequality in the welfare state: Sex segregation in housework. American Journal of Sociology 115(5): 1480-1523.

Julier, A.P. 2005. Hiding gender and race in the discourse of commercial food consumption. In From Betty Crocker to feminist food studies: Critical perspectives on women and food, eds. A.V. Avakian and B. Haber, 163184. Amherst, MA: University of Massachusetts Press.

Kan, M.Y. 2008. Measuring housework participation: The gap between "stylised" questionnaire estimates and diarybased estimates. Social Indicators Research 86(3): 381-400.

Lachance-Grzela, M., and G. Bouchard. 2010. Why do women do the lion's share of housework? A decade of research. Sex roles 63 (11-12): 767-780.

Lennon, M.C., and S. Rosenfield. 1994. Relative fairness and the division of housework: The importance of options. American Journal of Sociology 100: 506- 531.

Lennon, M.C., G. Wasserman and R. Allen. 1990. Husband's involvement in childcare and depressive symptoms among mothers of infants. Women and Health 17: 1-23.

Levenstein, H. 2003. Revolution at the table: the transformation of the American diet. Berkeley, CA: University of California Press.

Little, J., B. Ilbery and D. Watts. 2009. Gender, consumption and the relocalisation of food: A research agenda. Sociologia Ruralis 49 (3): 201- 217.

Lobao, L., and K. Meyer. 1995. Economic decline, gender and labor flexibility in family-based enterprises: Midwestern farming in the 1980s. Social Forces 74 (2): 575-608.

Lockie, S., and S. Kitto. 2000. Beyond the farm gate: production-consumption networks and agri-food research. Sociologia Ruralis 40 (1):3-19.

Lorber, J. 2010. Gender inequality: Feminist theories and politics. New York, NY: Oxford University Press.

Lundberg, U. 1996. Influence of paid and unpaid work on psychophysiological stress responses of men and women. Journal of Occupational Health Psychology 1 (2): 117.

Lundberg, U. 2002. Psychophysiology of work: Stress, gender, endocrine response, and work- related upper extremity disorders. American Journal of Industrial Medicine 41 (5): 383- 392.

Lundberg, U. 2005. Stress hormones in health and illness: The roles of work and gender. Psychoneuroendocrinology 30: 1017-1021.

Magnusson, M., A. Arvola, U. Hursti, L. Aberg, and P. Sjoden. 2003. Choice of organic foods is related to perceived consequences for human health and to environmentally friendly behavior. Appetite 40: 109-117.

Martinez, S., M. Hand, M. Da Pra, S. Pollack, K. Ralston, T. Smith, S. Vogel, S. Clark, L. Lohr, S. Low and C. Newman. 2010. Local food systems: Concepts, impacts and issues. Economic Research Report No. (ERR97) $87: 1-87$. 
McIntosh, W.A., and M. Zey. 1998. Women as gatekeepers of food consumption: A sociological critique. In Food and gender: Identity and power, eds. C. M. Counihan and S. L. Kaplan, 125-144. Amsterdam, Netherlands: Harwood Academic Publishers.

McMichael, P. 2000. The power of food. Agriculture and Human Values 17 (1): 21-33. Meares, A. 1997. Making the transition from conventional to sustainable agriculture: Gender, social movement participation, and quality of life on the family farm. Rural Sociology 62 (1): 21-47.

Mount, P. 2012. Growing local food: scale and local food systems governance. Agriculture and Human Values 29: 107-121.

Murdoch, J., and M. Miele. 2004. A new aesthetic of food? Relational reflexivity in the 'alternative food movement.' In Qualities of food, eds. M. Harvey, A. McMeckin, and A. Warde, 156-175. Manchester: Manchester University Press.

Ostrom, M. 2006. Everyday meanings of "local food": Views from home and field. Community Development 37 (1): 65-78.

Renting, H., T.K. Marsden, and J. Banks. 2003. Understanding alternative food networks: Exploring the role of short food supply chains in rural development. Environment and Planning A 35 (3): 393-412.

Risman, B.J. 2009. From doing to undoing: Gender as we know it. Gender and Society 23 (1): 81-84.

Sachs, C.E. 1996. Gendered fields: Rural women, agriculture, and environment. Boulder, CO: Westview Press.

Sanchez, L. and E. Thomson. 1997. Becoming mothers and fathers: Parenthood, gender, and the division of labor. Gender \& Society 11 (6): 747-772.

Schifferstein, H.N.J., and P.O. Ophuis. 1998. Health-related determinants of organic food consumption in the Netherlands. Food Quality and Preference 9: 119-133.

Shapiro, L. 2005. "I guarantee": Betty Crocker and the woman in the kitchen. In From Betty Crocker to feminist food studies: Critical perspectives on women and food, eds. A.V. Avakian and B. Haber, 29-40. Amherst, MA: University of Massachusetts Press.

Slocum, R. 2007. Whiteness, space and alternative food practice. Geoforum 38 (3): 520-533.

Som Castellano, R.L. 2013. Cooking up change? Alternative agrifood practices and the labor of food provisioning. Doctoral dissertation, The Ohio State University, Columbus, Ohio.

Trauger, A. 2004. 'Because they can do the work': Women farmers in sustainable agriculture in Pennsylvania. Gender, Place and Culture 11 (2): 290-307.

Vermeir, I., and W. Verbeke. 2006. Sustainable food consumption: Exploring the consumer "attitude - behavioral intention” gap. Journal of Agricultural and Environmental Ethics 19: 169-194.

West, C., and D.H. Zimmerman. 1987. Doing gender. Gender \& Society 1 (2): 125-151. Whatmore, S. 1991. Farming women: Gender, work, and family enterprise. London, UK: MacMillan.

Witt, S.D. 1997. Parental influence on children's socialization to gender roles. Adolescence 32 (126): 253-259. 
Table 1. State of Ohio Population Characteristics Compared with Sample (N=703)

\begin{tabular}{|l|l|l|}
\hline Variables & Ohio (\%) & Respondents (\%) \\
\hline Sex & & \\
\hline Male & 49 & 44 \\
\hline Female & 51 & 56 \\
\hline Race/Ethnicity & & \\
\hline African American & 12 & 3 \\
\hline Asian & 2 & 1 \\
\hline Hispanic/Latino(a) & 3 & 1 \\
\hline Native American/American Indian & 0 & 1 \\
\hline White & 82 & 93 \\
\hline Other & 2 & 2 \\
\hline Educational Attainment & 87 & 96 \\
\hline \% High School Grad or higher & 87 & 96 \\
\hline \% Bachelor's Degree or higher & 24 & 40 \\
\hline Married-couple Households & 49 & 62 \\
\hline Households with Individuals under 18 years of age & 32 & 27 \\
\hline Households with Individuals 65 Years and Over & 25 & 27 \\
\hline Home Ownership & & \\
\hline Owner-Occupied Housing Units & 69 & 85 \\
\hline Renter-Occupied Housing Units & 31 & 13 \\
\hline Household Income & & \\
\hline LT \$10,000 & 5 & 4 \\
\hline \$10,000 to 49,999 & 36 & 33 \\
\hline \$50,000 to 99,999 & 37 & 20 \\
\hline \$100,000 or more & 22 & \\
\hline Employment Status & 65 & 34 \\
\hline Employed & 35 & \\
\hline Unemployed & & \\
\hline
\end{tabular}


Table 2: Descriptive Statistics ( $\mathrm{N}=703)$

\begin{tabular}{|c|c|c|}
\hline Variables & Mean or $\%$ & SD \\
\hline $\begin{array}{l}\text { Frequency of Purchasing Local \& } \\
\text { Shopping Via Direct Markets }\end{array}$ & 6.7 & 2.2 \\
\hline $\begin{array}{l}\text { Buy foods that are locally grown or } \\
\text { produced }\end{array}$ & 3.7 & 1.2 \\
\hline Attend a farmers' market & 3.0 & 1.3 \\
\hline $\begin{array}{l}\text { Frequency of Purchasing Organic } \\
\text { and Shopping at Natural Grocery } \\
\text { Stores }\end{array}$ & 4.9 & 2.7 \\
\hline $\begin{array}{l}\text { Buy foods labeled as certified } \\
\text { organic }\end{array}$ & 2.7 & 1.5 \\
\hline $\begin{array}{l}\text { Shop at an organic or natural grocery } \\
\text { store (such as Whole Foods) or a } \\
\text { food coop }\end{array}$ & 2.2 & 1.4 \\
\hline \multicolumn{3}{|l|}{$\begin{array}{l}\text { Responsibility for Food } \\
\text { Provisioning }\end{array}$} \\
\hline Planning & 1.7 & .88 \\
\hline Shopping & 1.8 & .93 \\
\hline Cooking & 1.8 & .89 \\
\hline Cleaning & 1.9 & .98 \\
\hline \multicolumn{3}{|l|}{ Dependent Variables } \\
\hline Time Spent & 66.2 & 47.5 \\
\hline Proportion from Scratch & 40.8 & 32.4 \\
\hline \multicolumn{3}{|l|}{ Independent Variable of Interest } \\
\hline \multicolumn{3}{|l|}{ Gender } \\
\hline Male (0) & $44 \%$ & \\
\hline Female (1) & $56 \%$ & \\
\hline \multicolumn{3}{|l|}{ Control Variables } \\
\hline Age & 56.3 & 15.5 \\
\hline \multicolumn{3}{|l|}{ Presence of Children } \\
\hline Ages 0-4 & $18.1 \%$ & \\
\hline Ages 5-18 & $22.5 \%$ & \\
\hline \multicolumn{3}{|l|}{ Partnership Status } \\
\hline Partner (1) & $68.9 \%$ & \\
\hline No Partner $(0)$ & $31.2 \%$ & \\
\hline \multicolumn{3}{|l|}{ Employment Status } \\
\hline Employed (1) & $55.8 \%$ & \\
\hline Not Employed (0) & $44.2 \%$ & \\
\hline \multicolumn{3}{|l|}{ SES } \\
\hline \multicolumn{3}{|l|}{ Income } \\
\hline LT \$9,999 & $3.7 \%$ & \\
\hline$\$ 10,000$ to 19,999 & $8.9 \%$ & \\
\hline$\$ 20,000-34,999$ & $17.8 \%$ & \\
\hline$\$ 35,000-49,999$ & $17.2 \%$ & \\
\hline
\end{tabular}




\begin{tabular}{|l|l|l|}
\hline$\$ 50,000-74,999$ & $20.1 \%$ & \\
\hline$\$ 75,999-99,999$ & $12.5 \%$ & \\
\hline \$100,000 or more & $19.8 \%$ & \\
\hline Home Ownership & & \\
\hline Home Owner (1) & $81.2 \%$ & \\
\hline Not Home Owner (0) & $14.7 \%$ & \\
\hline Education & 14.6 & 2.9 \\
\hline Race & & \\
\hline White & $93.9 \%$ & \\
\hline African American & $2.9 \%$ & \\
\hline Hispanic/Latino(a) & $.6 \%$ & \\
\hline Asian & $.9 \%$ & \\
\hline American Indian & $.6 \%$ & \\
\hline Other & $1.2 \%$ & \\
\hline Gender Ideology & 3.0 & 2.1 \\
\hline Human Health Concern & 11.9 & 2.1 \\
\hline
\end{tabular}

Table 3. Results of the Bivariate Analyses, Proportion of Women and Men Responsible for Food Provisioning ${ }^{7}$

\begin{tabular}{|c|c|c|c|c|c|c|c|c|c|}
\hline & \multicolumn{3}{|c|}{$\begin{array}{l}\text { Entire Sample (\%) } \\
(\mathrm{n}=703)\end{array}$} & \multicolumn{3}{|c|}{$\begin{array}{l}\text { Engaged Local (\%) } \\
(\mathrm{n}=362)\end{array}$} & \multicolumn{3}{|c|}{$\begin{array}{l}\text { Engaged Organic (\%) } \\
(\mathrm{n}=181)\end{array}$} \\
\hline & Men & Women & Shared & Men & Women & Shared & Men & Women & Shared \\
\hline Planning & 16 & 59 & 24 & 13 & 63 & 24 & 11 & 57 & 32 \\
\hline Shopping & 18 & 50 & 32 & 15 & 53 & 32 & 15 & 48 & 37 \\
\hline Cooking & 17 & 57 & 26 & 14 & 58 & 28 & 16 & 54 & 30 \\
\hline Cleaning & 21 & 45 & 34 & 18 & 45 & 36 & 20 & 40 & 40 \\
\hline
\end{tabular}

\footnotetext{
${ }^{7}$ A small percentage of respondents reported that tasks were performed by someone other than the primary adults in the household. Therefore percentages may not total to 100.
} 


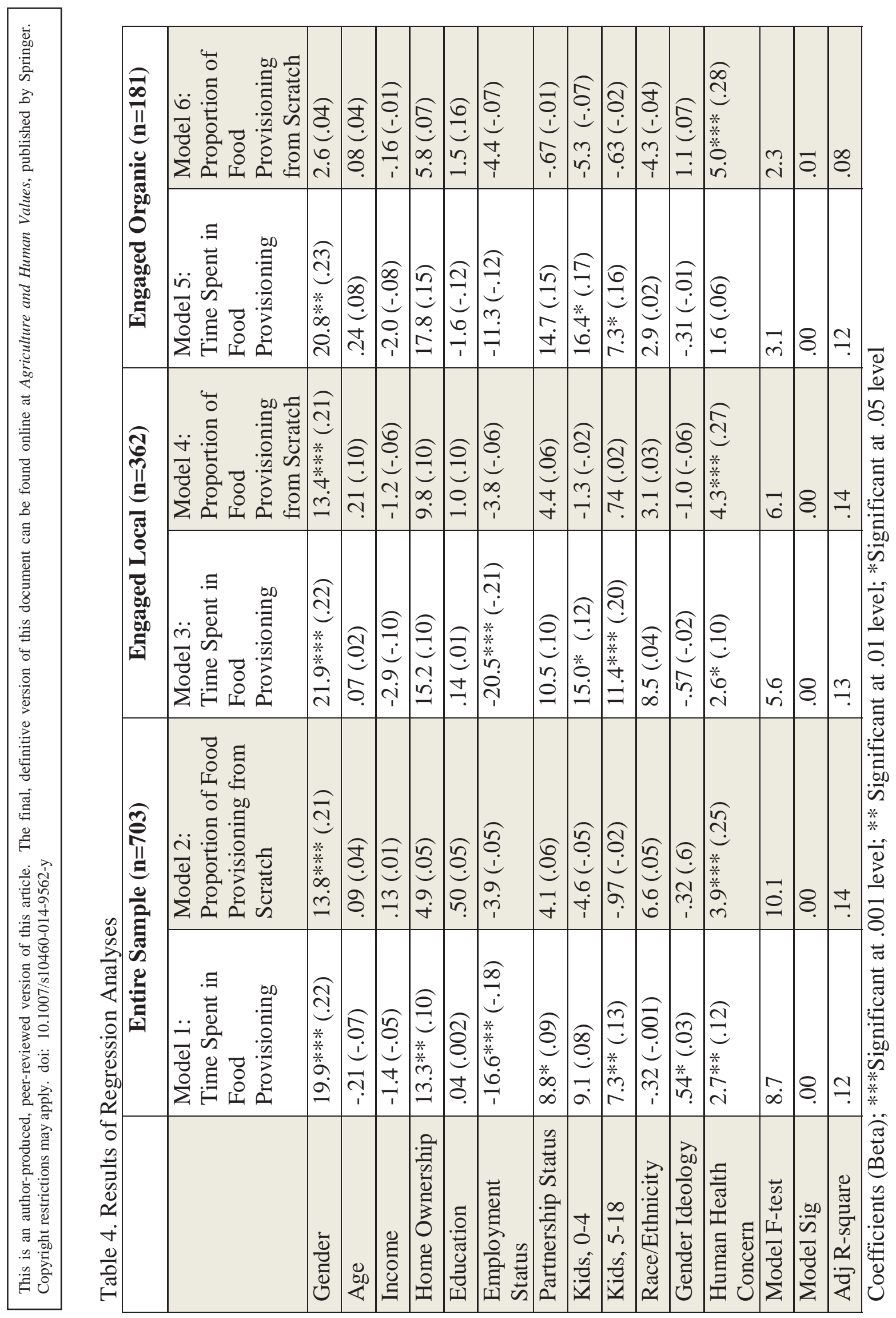

